\title{
A newly developed test rig for the study of thermal fatigue
}

\author{
M. Fazarinc, R. Turk, G. Kugler \& M. Terčelj \\ Department of Materials and Metallurgy, \\ Faculty of Natural Sciences and Engineering, University of Ljubljana, \\ Aškerčeva cesta 12, 1000 Ljubljana, Slovenia
}

\begin{abstract}
For simulation and better study of thermal fatigue, a new test rig has been developed. The rig has computer guided heating and quenching of the specimen that enables constant thermal loading and gathering of reliable experimental data. At the same maximal testing temperature it is possible to generate different and higher temperature gradients in comparison to other tests. The cooling rates that were measured were almost $4000{ }^{\circ} \mathrm{C} / \mathrm{s}$, which is considerably higher than the known rates so far measured (calculated) in cases of thermal fatigue cases (500 $1000{ }^{\circ} \mathrm{C}$ ) and thus fewer cycles to crack nucleation were needed. Verification of the abilities of the rig was carried out with specimens (AISI H11 tool steel) which had different wall thicknesses $(2.75-4 \mathrm{~mm})$ and different surface qualities (heat treated and gas nitrided). The gas nitrided specimens exhibited lower thermal fatigue resistance. The shape of cracks was a grid, which is a typical characteristic of tools subjected to thermal fatigue (tools for hot forming of materials, etc.). Some specimens were additionally mechanically loaded and cracks that were at right-angles to the direction of the compression force were essentially detained; their nucleation and growth were suppressed. The measured temperatures in the surface layer were used to calculate the initial stress field using the Finite Element Method (FEM). The computed results matched well with the experimental data on the number of cycles needed for crack initiation. Keywords: test rig, thermal fatigue, tool steel AISI H11, FEM analysis.
\end{abstract}




\section{Introduction}

Thermal shock and/or fatigue resistance are very important characteristics of a material. The laboratory test rig (equipment) for their evaluation must be capable of carrying out such tests at various temperatures and have the capability, at the same testing temperature, to generate various temperature (stress) fields in order to better evaluate the usage of materials for a specific application. The tests that can be found in the literature cannot fulfil the above mentioned tasks satisfactorily. Poor knowledge of the temperature field within the specimen and consequently also poor knowledge of the stress/strain field results in an inaccurate estimation of the influence of parameters that are responsible for the nucleation and growth of cracks. In the past years an increased demand for improvement experimental data for better numerical modelling of crack growth can be found in the literature. Quenching in water is a very popular method to measure of thermal shock or thermal fatigue resistance but it has some weaknesses due to the unknown (unstable) heat transfer coefficient as a consequence of the vaporisation of water in the vicinity of the tested specimen surface [1-4]. Some authors designed special nozzles in order to minimize the effect of water vaporisation [5]. Marsh [6], Amiabe et al. [4] and Hadder and Fissolo [7] applied the so-called SPLASH test that also utilises water quenching of samples to generate temperature fields. Although they made great progress in modelling of crack growth on the basis of the experimental data further experimental improvements in this research area are desired.

Therefore the goal of this paper was to present a new test rig for better evaluation of thermal shock or thermal fatigue resistance of materials. This test rig enables generation of high thermal stress with well defined thermal boundary conditions which allows the study of the temperature and thermal stress distribution in order to better evaluate the thermal shock or fatigue resistance of the tested material. An especially desirable characteristic of the test should have be the ability to generate various stress fields in the tested sample at the same maximal temperature.

\section{Experimental set-up}

\subsection{Test rig and testing parameters}

For obtaining reliable test date it is of a great importance that the test is computer controlled and thus highly repeatable. Thus it was found helpful to carry out the tests on a thermo-mechanical simulator of metallurgical states, the Gleeble $1500 \mathrm{D}$, in order to utilize the possibility of computer guided resistance heating of specimens and movement of the working jaws, simultaneously. The main idea was that the specimens would be rapidly heated to the maximum holding temperature and then the surface would be quenched with water. It was estimated that the cracks would form earlier than in 1000 cycles (for tool steel); this would shorten the testing time of a given specimen. 
Circular and hollow shaped specimens were applied for testing (Figure 1). The thermocouple (type K) needed for temperature control and guidance was welded inside the specimen in the middle of its testing area, as shown on Figure 1. The outer testing part of the specimen was placed in a cooling chamber (Figure 2). The cooling and emptying process was optimized by a pair of magnetic computer controlled valves. One valve controlled the water quench and the other controlled the air compression to empty the cooling chamber. The valves were guided using the Gleeble 1500D control computer that was programmed simultaneously with the program for thermal and mechanical loading of the specimen.

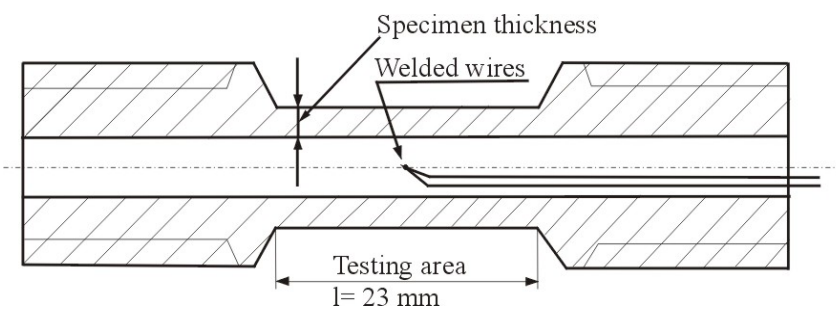

Figure 1: Cross section of the testing specimen with welded wires.

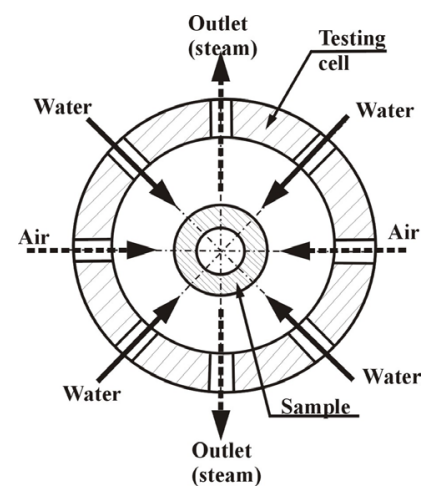

Figure 2: The cooling chamber with water cooled clamps.

The setup of the test rig, without working jaws, is shown in Figure 3a and it's positioning in the Gleeble load cell is shown in Figure $3 \mathrm{~b}$.

For proving the test's abilities of the test rig, nine different specimens (made from AISI H11 tool steel) with various characteristics given in Table 1 were tested. Two different types of specimens were compared, i.e. five were heat treated (I - IV and IX, initial microstructure on Figure 4a) and four were heat treated plus gas nitrided (V - VIII, initial microstructure on Figure 4b). Further, the specimens differed also in specimen thickness $(2.75-4 \mathrm{~mm})$. Two specimens of each mentioned types were also mechanically loaded during testing by applying a compression force $(0-19 \mathrm{kN})$ equal to $90 \%$ of the yield stress at $650^{\circ} \mathrm{C}$ corresponding to a value around $150 \mathrm{MPa}$. 
The program used for thermal and mechanical loading (see Figure $5 \mathrm{a}-\mathrm{b}$ ) of the specimen was written in the applicative program QuickSim and was composed in following way:

- resistance heating of the sample to the holding temperature of $650^{\circ} \mathrm{C}$ with increasing mechanical loading ( 0 to $19 \mathrm{kN}$, see Figure $5 \mathrm{a}-\mathrm{b}$ ),

- water quenching (0-0.50s) during maintenance of the programmed temperature and mechanical loading,

- $\quad$ interruption of heating and quenching (and mechanical unloading),

- blowing of compressed air into the chamber (3s).

After 500 cycles the tested surface was examined visually and after 1000 cycles the specimens were cut and metallographically prepared for microscopic analysis.

Table 1: Characteristics of specimens (AISI H11) and loadings (thickness $[\mathrm{mm}])$.

\begin{tabular}{|l|c|c|c|c|c|c|c|c|c|}
\hline $\begin{array}{l}\text { Surface } \\
\text { treatment }\end{array}$ & \multicolumn{2}{|c|}{ Heat treated } & \multicolumn{2}{c|}{$\begin{array}{c}\text { Heat } \\
\text { treated }\end{array}$} & \multicolumn{2}{c|}{$\begin{array}{c}\text { H.T. }+ \\
\text { nitrided }\end{array}$} & \multicolumn{2}{c|}{$\begin{array}{c}\text { H.T. }+ \\
\text { nitrided }\end{array}$} & $\begin{array}{c}\text { Heat } \\
\text { treated }\end{array}$ \\
\hline Specimen & I & II & III & IV & V & VI & VII & VIII & IX \\
\hline Thickness & 2.75 & 3.25 & 2.75 & 3.25 & 2.75 & 3.25 & 2.75 & 3.25 & 4 \\
\hline $\mathrm{T}_{\max }\left({ }^{\circ} \mathrm{C}\right)$ & \multicolumn{2}{|c|}{650} & \multicolumn{2}{|c|}{650} & \multicolumn{2}{c|}{650} & \multicolumn{2}{c|}{650} & 650 \\
\hline $\mathrm{F}_{\max }(\mathrm{kN})$ & \multicolumn{2}{|c|}{0} & \multicolumn{2}{|c|}{-19.0} & \multicolumn{2}{c|}{0} & \multicolumn{2}{c|}{-19.0} & 0 \\
\hline
\end{tabular}
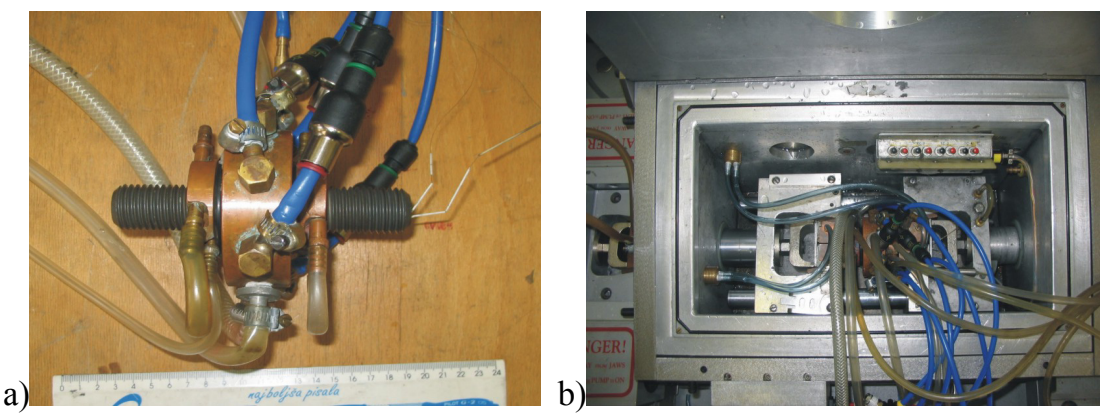

Figure 3: a) Testing device with specimen, b) Inserted test rig in testing cell.
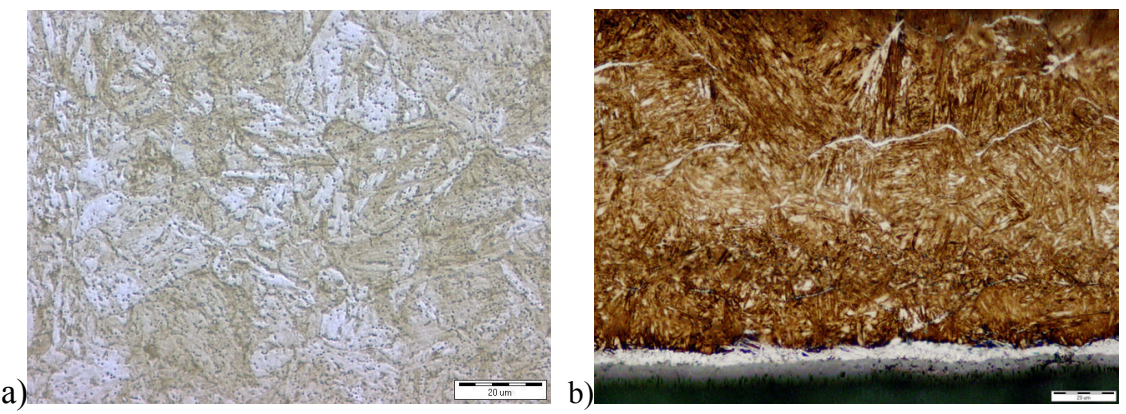

Figure 4: $\quad$ Microstructure a) Heat treated specimens, b) Nitrided specimens. 


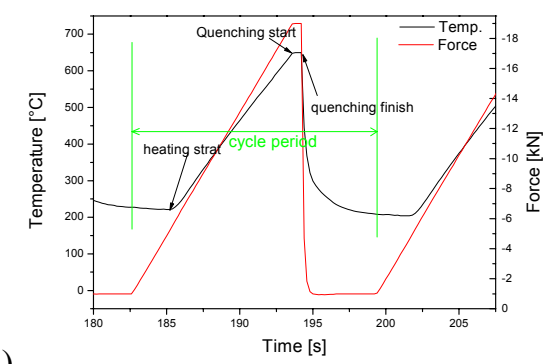

a)

Figure 5: a) The thermal and mechanical loading in one cycle, b) 50 temperature cycles.

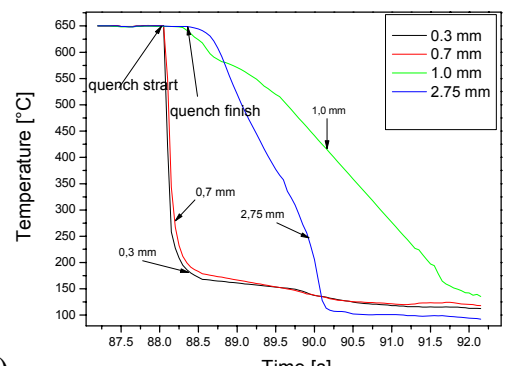

a) Time [s]

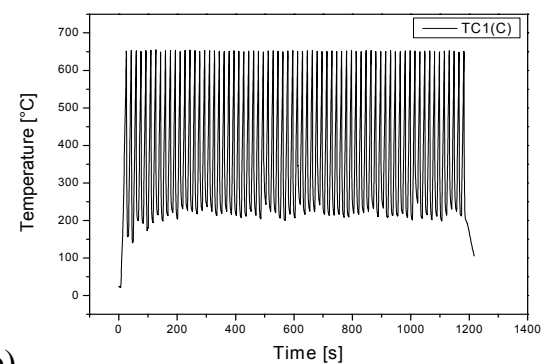

b)

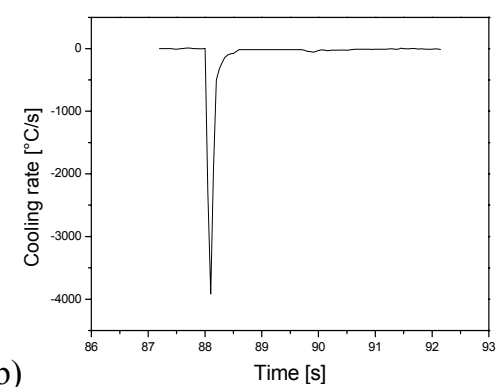

Figure 6: a) Measured temperatures at different depths during the quenching sequence, b) Cooling rate at the depth of $0.30 \mathrm{~mm}$.
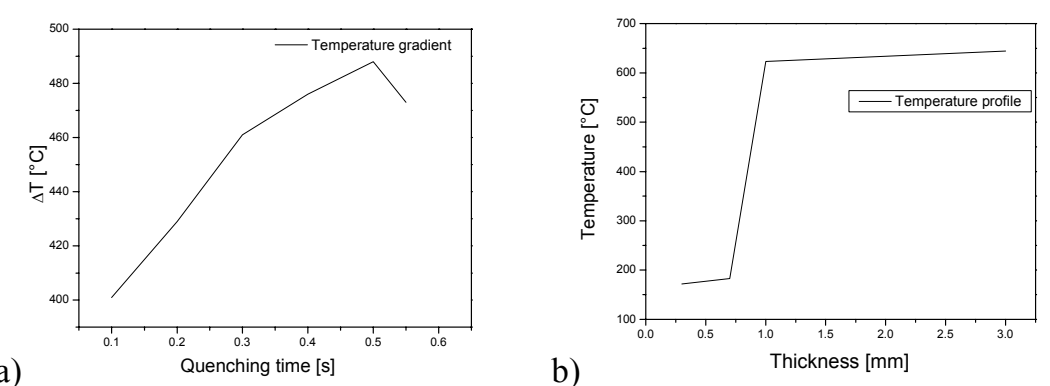

Figure 7: a) Measured minimal temperature (temperature profile) in various depths at quenching time of $0.5 \mathrm{~s}, \mathrm{~b}$ ) Measured temperature gradient in the specimen at various quenching times.

\section{Results}

\subsection{Measurements of temperature in the specimen}

A typical example of a thermal and mechanical cycle is shown in Figure 5a. The simultaneous increasing of temperature and mechanical loading of the tested 
specimen is visible, while during quenching both of them maintain the programmed (same) value. The repetitiveness of the testing cycles obtained is presented on Figure 5b. The temperature of the specimen was controlled by the thermocouple, as presented in Figure 1.

In order to determine (measure) the temperature field on the tested surface, a specially made specimen was applied in which inside had welded three additional highly responsive thermocouples (wire diameter $0.2 \mathrm{~mm}$, type $\mathrm{K}$ ) on various distances $(0.30 \mathrm{~mm}, 0.70 \mathrm{~mm}, 1 \mathrm{~mm})$ bellow quenched surface, while the fourth thermocouple (Figure 1) served for computer guidance and control of temperature. Their measured values are shown in Figure 6a. It is apparent that the temperature of the fourth and computer guided thermocouple remained at the programmed value of $650{ }^{\circ} \mathrm{C}$ also during quenching. After the quenching period the temperature fall of the fourth thermocouple was higher in comparison to the third thermocouple, since the heat transfer on the outer surface in the hollow specimen is also higher. The highest temperature gradient was registered at the quenching time of $0.5 \mathrm{~s}$ where the measured temperature difference between the first and the fourth thermocouple was $473^{\circ} \mathrm{C}$. The cooling rate was determined by differentiating the temperature/time curve at the depth of $0.30 \mathrm{~mm}$ from the quenched surface. Using this technique the maximum cooling rate was determined $\left(3918{ }^{\circ} \mathrm{C} / \mathrm{s}\right.$, Figure $\left.6 \mathrm{~b}\right)$. At the specimen surface these rates were certainly higher. Thus with a combination of simultaneously controlled cooling and resistance heating of the specimen, greater thermal gradients in relatively thin specimen surface layer were achieved, while the remaining depth of the specimen kept approximately the same value (see Figures 5a and 6a). This reduced the number of cycles needed for crack nucleation and resulted in faster crack growth. For comparison Hadder and Fissolo [7] and Marsh [6] report cooling rates between 500 and $1000{ }^{\circ} \mathrm{C} / \mathrm{s}$. The minimal measured temperature for the first thermocouple and various quenching times $(0.1-0.55 \mathrm{~s})$ are shown in Figure $7 \mathrm{a}$ while Figure $7 \mathrm{~b}$ shows the temperature profile (field) in the tested specimen at a quenching time of $0.5 \mathrm{~s}$. With the possibility of generation of various thermal gradient, the test can also simulate various thermal loading conditions in an applicative environment.

\subsection{Estimation of initial stress field by FEM}

When the entire temperature profile was known the FEM was applied in order to estimate initial stress field (thermal stress) for different quenching times and specimen thicknesses. The MSC Super Forge 2005 code was used for this. The results of these analyses are shown in Figure $8 \mathrm{a}-\mathrm{b}$. The analyses show that the maximum stresses are obtained after $0.5 \mathrm{~s}$ of quenching and are roughly $140 \mathrm{MPa}$ for a specimen thickness of $2.75 \mathrm{~mm}$. At $0.12 \mathrm{~s}$ of quench time the stresses reached the values around $125 \mathrm{MPa}$. This shows that the temperature and consequently the stress field can be varied by changing the quenching time. The stress obtained also depends on specimen thickness; thus they reached values of cca $160 \mathrm{MPa}$ and $175 \mathrm{MPa}$ for specimen thicknesses of $3.25 \mathrm{~mm}$ and $4 \mathrm{~mm}$, respectively. Furthermore the temperature can be varied by changing the quenching liquid (nitrogen, air, etc) and changing its pressure. 
a)
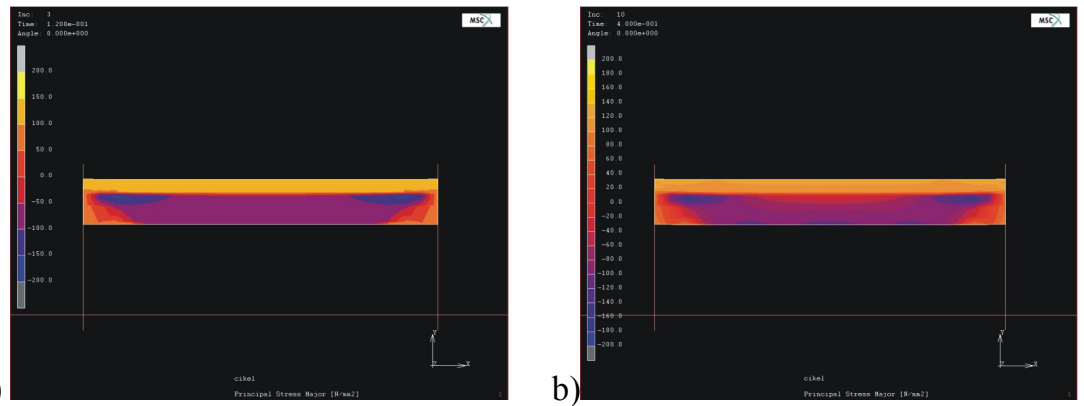

Figure 8: Estimated stress field simulated by FEM method, a) $t=0.12 \mathrm{~s}$, b) $\mathrm{t}=0.5 \mathrm{~s}$; wall thickness $2.75 \mathrm{~mm}, \mathrm{~T}=650{ }^{\circ} \mathrm{C}$.

\subsection{Appearance of surface cracking}

From the estimated stress field it could be predicted that cracks would appear in thicker specimens sooner than in thinner specimens. The next batch of pictures were taken by an optical microscope after 1000 cycles of testing. The results are given in sequences according to thickness.

\subsubsection{Wall thickness $2.75 \mathrm{~mm}$}

Estimated initial maximal stresses for the wall thickness of $2.75 \mathrm{~mm}$ were namely around $140 \mathrm{MPa}$ that is lower as yield stress of AISI H11 tool steel at $650{ }^{\circ} \mathrm{C}$ (cca $\left.150 \mathrm{MPa}\right)$. This fact explain why on heat treated no cracks occurred but on contrary on gas nitrided specimens network of cracks was observed after 1000 cycles; the depth of obtained crack was in range 20 - $60 \mu \mathrm{m}$ (Figure 9).

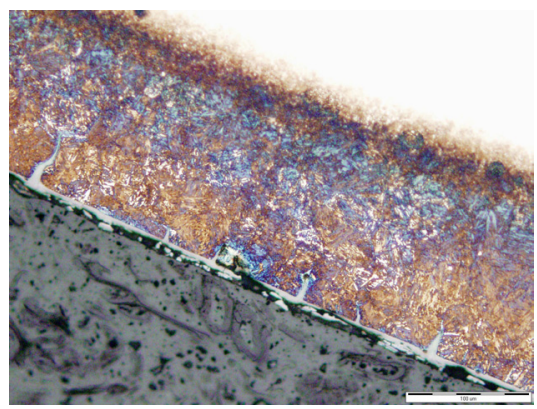

Figure 9: Appearance of surfaces of nitrided specimens after 1000 cycles, axially unloaded specimen; quenching time $0.5 \mathrm{~s}$, thickness 2.55 $\mathrm{mm}$, radial cross-section.

\subsubsection{Wall thickness $3.25 \mathrm{~mm}$}

The next batch of pictures was taken on nitrided specimens after 1000 cycles where the thickness of the specimens was $3.25 \mathrm{~mm}$. Estimated maximal stress using the FEM wall thickness of the specimen $3.25 \mathrm{~mm}$ amounted around 
$160 \mathrm{MPa}$. Consequently the cracks appearing were deeper and denser. Figure 10a shows the surface of nitrided specimen after 1000 cycles. The cracks here are clearly visible and they are appearing in both directions (radial and axial). As expected, the axial loading of the specimen restricted the nucleation of cracks in the radial direction. The maximal compression force during cooling was $19 \mathrm{MN}$ corresponding cca $140 \mathrm{MPa}$. Thus it means that maximal stresses in axial direction of the specimen were close to zero and consequently no cracks appeared in the radial direction (Figure 10b). The depths of the obtained cracks in the radial direction for an axially unloaded specimen are presented on Figure $11 \mathrm{a}$ and for an axially loaded specimen on Figure 11b. The crack depth obtained was cca $180 \mu \mathrm{m}$ in the radial direction and cca $120 \mu \mathrm{m}$ in the axial direction. The same phenomenon also occurred on heat treated specimen, only the depth of the cracks were lower (cca 20-30 $\mu \mathrm{m})$.

a)

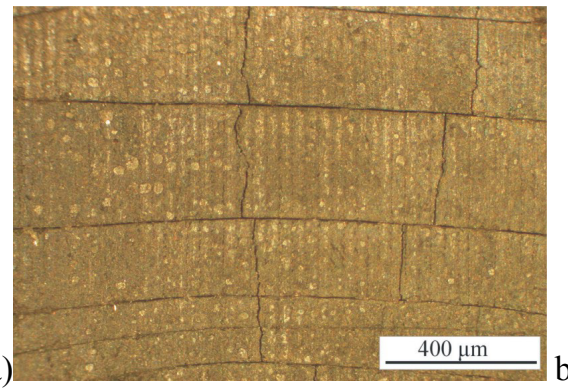

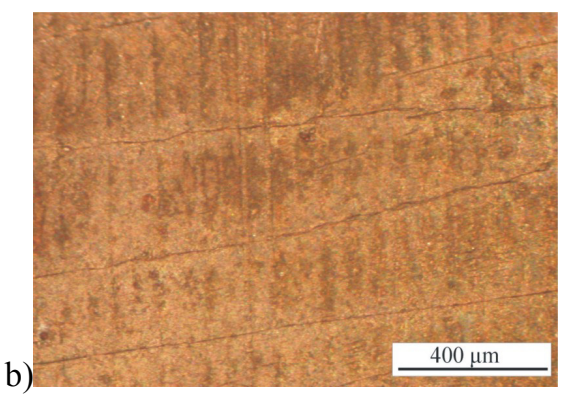

Figure 10: Appearance of surface of nitrided specimens after 1000 cycles, a) Axially unloaded specimen, b) Axially loaded, $\leftarrow$ direction of axial loading; quenching time $0.3 \mathrm{~s}$, and thickness $3.25 \mathrm{~mm}$.
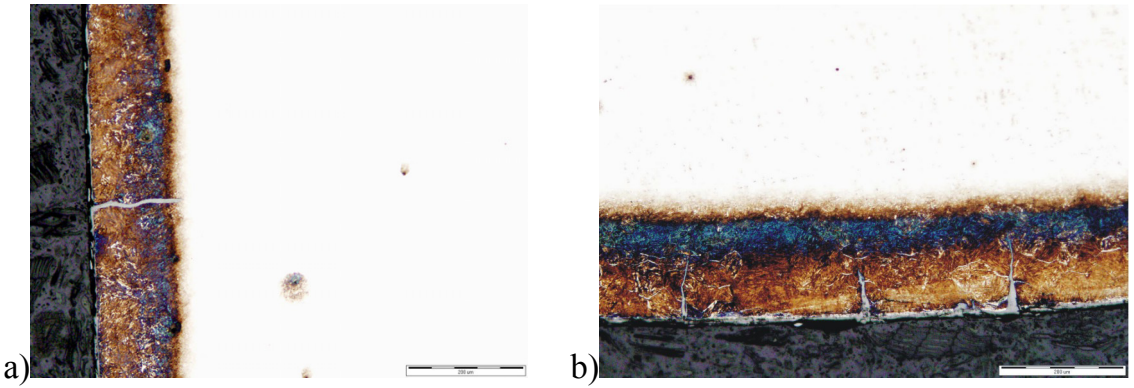

Figure 11: Cross-section of nitrided specimen of axially loaded nitrided specimens, a) Axial section, b) Radial section; quenching time $0.3 \mathrm{~s}$, wall thickness $3.25 \mathrm{~mm}$.

\subsubsection{Wall thickness $4 \mathrm{~mm}$}

As was expected denser cracks were obtained in thicker specimen and at a quenching time of $0.5 \mathrm{~s}$ since the estimated maximal stress (for the specimen thicknesses of $4.0 \mathrm{~mm}$ ) amounted around $170 \mathrm{MPa}$. On Figure $12 \mathrm{a}-\mathrm{b}$ the cracks 
network on heat treated specimen is visible. Mentioned cracks were visible still after 500 quenching cycles and after 1000 quenching cycles the crack net obtained was denser. The depth of the cracks was around $40 \mu \mathrm{m}$.

\subsubsection{Discussion}

The test enables us to vary all important parameters which influence the experimental results. These are the heating rate, maximum specimen temperature, quenching time, quenching medium, pressure of the quenching medium, specimen wall thickness, and the external specimen loading (tensile compressive, cyclic - constant). The appearance of cracks on tested specimen was very similar to those obtained on a hot working surface of rolls as presented on Figure 13. Namely, after its contact with heated specimen the roll surface is subjected to rapid water cooling leading to surface cracking.

In the literature we can find contradictory result regarding to the thermal fatigue resistance of some nitrided surfaces. Thus Pellizari et al. [8] claim that nitrided surfaces decreased the fatigue resistance on the contrary Spies et al. [9] claim that the nitrided surface increased fatigue resistance. The authors did not present the temperature field and consequently they also could not calculate (asses) the stress field (predominately tensile or compression stresses) on the tested specimens from which the reason for the appearance of cracks based. Therefore, different results should be carefully compared according to the specific test conditions.

a)

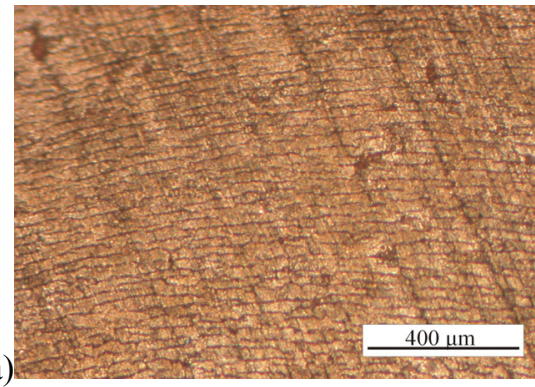

b)

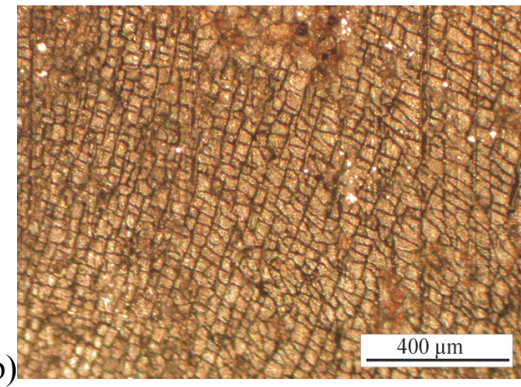

Figure 12: Appearance of the surface of heat treated specimens, a) After 500 cycles, b) After 1000; axially unloaded specimen, quenching time $0.5 \mathrm{~s}$, wall thickness $4 \mathrm{~mm}$, heat treated.

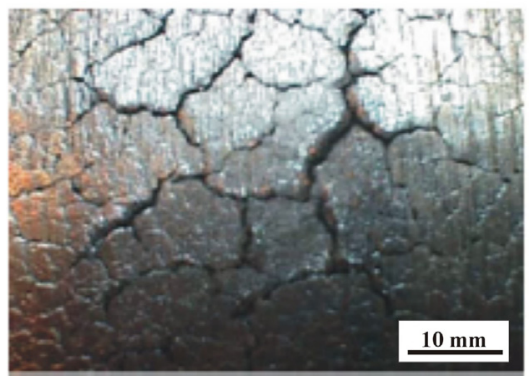

Figure 13: Appearance of cracks on the surface of hot roll. 


\section{Conclusions}

A new thermal fatigue test was developed for testing materials. It is based on computer guided heating and quenching of the specimen. The specific shape of the specimen and special execution of the program enables the achievement of very high temperature gradients that are greater than those found in the literature. This reduces the number of cycles needed for crack nucleation and enables shorter testing times. In combination with mechanical loading different stress states on specimens can be achieved (mechanical pre-loading of forging tools, etc.). The test can generate a wide range of conditions to which the real parts can be subjected. Calculation of the stress field using the FEM showed the highest stresses in the thicker walls of the specimen. Thus on specimens with thicker walls and longer cooling times, the cracks nucleated earlier and are denser. A comparison of two differently treated materials (heat treated or heat treated + gas nitrided) showed that the nitrided layer is brittle and rapidly cracks under tensile thermal stresses. The newly developed test with its proven characteristics will contribute to better understanding of crack nucleation and their growth. This is the basis for better modelling of the processes involved.

\section{References}

[1] A. Weroński, T. Hejwowski, Thermal fatigue of metals, Marcel Dekker 1991.

[2] N. Hadder, A. Fissolo, V. Maillot, Thermal fatigue crack networks: a computational study, International Journal of Solids and Structures 42 (2005) 771-788.

[3] A. Persson, S. Hogmark, J. Bergström, Simulation and evaluation of thermal fatigue cracking of hot work tool steel, International Journal of Fatigue 26 (2004) 1095-1107.

[4] S. Amiable, S. Chapuliot, A. Constantinescu, A. Fissolo, A comparison of life time prediction methods for a thermal fatigue experiment, International Journal of Fatigue, 28 (2006) 692-706.

[5] J. Absi, J.C. Glandus, Improved methods for severe thermal shocks testing of ceramics by water quenching, Journal of European Ceramic society 24 (2004) 2835-2838.

[6] D.J. Marsh, A thermal shock fatigue study of type 304 and 316 stainless steels, Fatigue of Engineering Materials and Structures, 4/2 (1981) 179195.

[7] N. Hadder, A. Fissolo, 2D simulation of the initiation and propagation of crack array under thermal fatigue, Nuclear Engineering and Design 235 (2005) 945-964.

[8] M. Pellizzari, A. Molinari, G. Straffelini, Thermal fatigue resistance of gas and plasma nitrided 41CrAlMo7 steel, Materials Science \& Engineering A352 (2003) 186-194.

[9] H.J. Spies, F. Vogt, M. Svennson, Neue Hütte 8 (1983) 281-287. 